\title{
Carmine as an Index of Transit Time in Children with Simple Constipation
}

\author{
S. B. DIMSON \\ From Sydenham Children's Hospital, and East Ham Memorial, London Jewish, andQueen Mary's (Stratford) \\ Hospitals
}

\begin{abstract}
Dimson, S. B. (1970). Archives of Disease in Childhood, 45, 232. Carmine as an index of transit time in children with simple constipation. The transit time of carmine through the alimentary canal has been estimated in 65 children with simple chronic constipation but without abdominal pain or faecal incontinence. Comparison was made with matched normal controls and as a result criteria have been suggested which, in conjunction with a complete physical examination, may help to differentiate the normal from the constipated. The carmine test is simple, acceptable, and valid, but though it cannot indicate the type of constipation present it may be useful in estimating its degree. In predominantly rectal constipation there was a significant reduction in severity of constipation in boys over the age of 6 years as compared with girls, possibly due to the supervention of faecal incontinence in boys which excluded them from this series.
\end{abstract}

Constipation is customarily defined as a condition in which bowel actions are infrequent and stools hard in consistency. This definition is incomplete, and Davidson, Kugler, and Bauer (1963) suggest that a possible history of blood-streaked motions (almost pathognomonic of an anal fissure), difficulty or 'straining' on defaecation, abdominal discomfort, and the use of laxatives or suppositories should be included to make the diagnosis certain. At least one of these criteria they thought was necessary to establish a history of constipation. Possibly the use of laxatives should be excluded as a criterion as they are often given by mothers without adequate cause (Reid, 1956).

However detailed the definition, it remains a subjective one, based as it is almost entirely on the history given by the mother. The results even of a careful abdominal, rectal, and anal examination may be inconclusive, more especially if the type of constipation present is colonic in origin. A more objective approach is clearly desirable, and this becomes possible if constipation is redefined as basically a delay in transit time. Indeed Hurst (1919) called it a 'condition in which none of the residue of a meal, taken 8 hours after defaecation, is excreted within $\mathbf{4 0}$ hours.' He regarded a patient as constipated if charcoal, taken with food under

Received 1 August 1969. these circumstances, is not visible, at the latest, the second morning after it was taken. Other methods of ascertaining the transit time included the ingese tion of carmine (Strauss, 1914), beads (Alvarez and Freedlander, 1924), millet seed (Burnett, 1923) and the use of $x$-rays (Hurst, 1919). Broadle speaking, barium studies show that with the bowels open daily, half the barium is excreted in 24 hours and the remainder within another 24 hours (Shanks. and Kerley, 1958). Recently transit times have् been investigated by Hinton and Lennard-Jones (1968) using radio-opaque pellets of a size shown to. travel at the same rate as carmine (Hinton, 1967) 8 in the absence of constipation excretion began within 72 hours in all the 25 adults studied and is 21 of them $80 \%$ of the pellets were excreted within that period, but some cases complaining of constio pation had a normal transit time though in most if: was prolonged.

As an out-patient research tool for large numbens of children the use of $x$-rays is unjustifiable, thes counting of beads or seed both time consuming and impracticable, and the more accurate and sophisticated methods used in delicate metabolic studies too laborious and expensive. If only $\underset{\mathbb{Q}}{\mathbb{Q}}$ rough guide to transit time, showing head and tait only, is required, colouring matter is preferables and the colour change after carmine is more striking than after charcoal. Its use as a marker in the 
collection of stools for fat analysis in children prompted the choice of carmine in the present study.

\section{Method and Material}

A gelatine capsule containing $0.3 \mathrm{~g}$. carmine was given to children during the morning of their first attendance after a careful abdominal, rectal, and anal examination which was carried out personally in all cases. If unable to swallow the capsule, its contents were given in water but, for young children especially, it was later found preferable to incorporate the carmine into jelly crystals as 'turkish delight' or into pastilles as described by Dykes, Harris, and Marston (1960). No difference was found in the readings obtained by these various methods of administration, which were usually acceptable, but occasionally accompanied by grimaces.

Mothers were asked to write down on the form provided the date and time when the stools changed colour and when they returned to normal, and to refrain from giving laxatives during the test. The form was usually returned one or two weeks later.

Results were recorded in days rather than in hours when it was found, contrary to expectation, that only about a third of the children studied had their bowels open before school, most of them waiting until they returned home in the late afternoon. The initial reading $(R)$ denotes the day in which the colour change was first noticed, and the final reading $(N)$ when the stools first became normal again. For example, R2N4 means that the stool turned partly red on the day after ingestion but resumed its normal colour on the fourth day; if no stool was passed on the third day, the reading was adjusted as R2N3. 'Nil' returns were inevitable, chiefly because defaecation occurred at school, but they were uncommon; if again 'nil' on repetition the test was abandoned. When positive results were repeated they gave consistent readings.

In order to establish the range, normal, and abnormal to be expected from this test, 65 children were selected who were definitely constipated on the basis of their history and on the result of a complete physical examination which generally showed the rectum, and sometimes the descending colon as well, to be loaded with hard faeces. The children had been referred usually because of anal discomfort, rectal pain, or 'straining' on passing hard stools, or constipation had been discovered as an incidental finding. The type of constipation was therefore predominantly rectal, corresponding to the enlarged or expanded rectum of Callaghan and Nixon (1964), but a few presented with colonic constipation in which the descending colon was palpable and tender with hard bits of faeces in the rectum.

To avoid the intrusion of extraneous factors which might have a direct or indirect bearing on the results of the carmine test, the selection of these children with simple chronic constipation was very rigid so as to exclude all with past or present soiling or encopresis, all with abdominal pain, headache, vomiting, a bleeding anal fissure, or long intervals between bowel actions, and all under the age of 3 years because of the possible uncertainty in very young children as to whether the site of the pain was in the rectum or in the abdomen.

There were 34 girls and 31 boys in this highly selected group who gave positive results to the carmine test, and their age and sex distribution are indicated in the Fig.

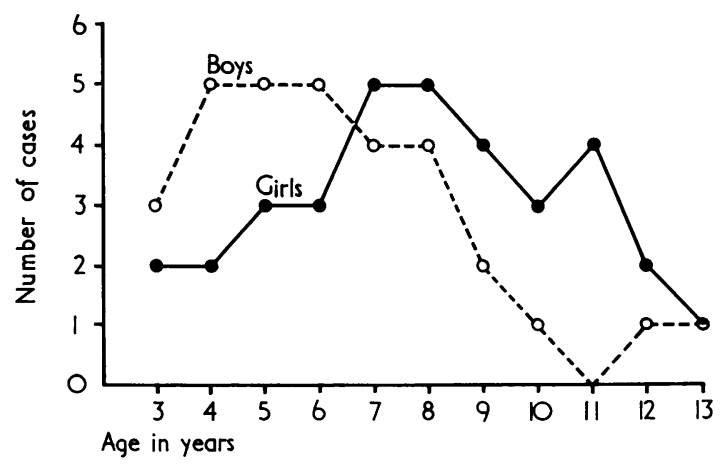

FIG.-Age and sex distribution of children with simple constipation.

It will be seen that boys are in the majority up to the age of 6 but girls predominate thereafter. 21 children (10 girls and 11 boys) had a history strongly suggestive of an anal fissure and some showed anal tags, but whereas 12 of them were between the ages of 3 and 6 , only 9 were between 7 and 12 years old, possibly because in these older children maternal memory was faulty.

These 65 children were matched according to age and sex with the same number of out-patients leading normal active lives who had one daily bowel action with no history of gastro-intestinal symptoms or headaches, and in whom constipation past or present had been excluded as far as possible. Though constituting the controls for this study, they do not necessarily represent the normal child population at large.

\section{Results}

Table I shows a highly significant difference $(p<0.0001)$ between the transit times of normal and constipated children. From the way they are distributed, the normal children are those whose stools became red on the first, second, or third days ( $R 1,2$ or 3 ), provided that the colour change had disappeared by the fourth day (N4). This proviso is introduced to try and differentiate normal children from those with cumulative or fragmentary constipation (Hurst) in whom the rectum never empties completely and only a small amount of faeces is passed on each occasion the bowels are open, whether this happens every day or not. N5 and over is therefore taken to mean that excretion is delayed, and a vertical line has been drawn to separate N4 from N5 plus. However, by this criterion, arbitrary though it may be, 4 of the 
TABLE I

Time of Appearance and Disappearance of Carmine Marker in Normal and Constipated Children

\begin{tabular}{|c|c|c|c|c|c|c|c|c|c|}
\hline & \multicolumn{2}{|c|}{$\begin{array}{c}\text { Initial } \\
\text { Reading (R) }\end{array}$} & \multicolumn{7}{|c|}{ Final Reading $(\mathrm{N})$ in Days } \\
\hline & Days & $\begin{array}{c}\text { No. } \\
\text { of } \\
\text { Cases }\end{array}$ & 2 & 3 & 4 & 5 & 6 & 7 & $>7$ \\
\hline Normal & $\begin{array}{l}1 \\
2 \\
3 \\
4\end{array}$ & $\begin{array}{r}4 \\
51 \\
9 \\
1\end{array}$ & & $\begin{array}{r}3 \\
23 \\
1\end{array}$ & $\begin{array}{r}1 \\
27 \\
6\end{array}$ & $\begin{array}{l}1 \\
1\end{array}$ & 1 & 1 & \\
\hline Total & & 65 & & 27 & 34 & 2 & 1 & 1 & \\
\hline $\begin{array}{l}\text { Simple } \\
\text { consti- } \\
\text { pation }\end{array}$ & $\begin{array}{l}1 \\
2 \\
3 \\
4 \\
5 \\
6 \\
7\end{array}$ & $\begin{array}{r}19 \\
23 \\
11 \\
7 \\
3 \\
2\end{array}$ & & 2 & $\begin{array}{l}1 \\
2\end{array}$ & $\begin{array}{r}8 \\
11 \\
4\end{array}$ & $\begin{array}{l}6 \\
3 \\
3 \\
4\end{array}$ & $\begin{array}{l}1 \\
4 \\
1 \\
2 \\
2\end{array}$ & $\begin{array}{l}1 \\
3 \\
3 \\
1 \\
1 \\
2\end{array}$ \\
\hline Total & & 65 & & 2 & 3 & 23 & 16 & 10 & 11 \\
\hline
\end{tabular}

$\chi^{2}=76.9 ; \mathrm{df}=1 ; \mathrm{p}<0.0001$.

normal children were constipated and 5 of the constipated children were normal (Table I). It is possible that a normal transit time in these constipated children was due to laxatives taken against advice, and that in the normal children delay resulted from constipation which was otherwise inapparent, or from readings erroneously recorded. Nevertheless, the level of consistency of the results is high despite these discrepancies. (3 children not included in Table I gave a 'nil' return due either to observer error or to the initial colour change being delayed into the second week, or to the theoretical possibility that very dark stools may obscure the colour of carmine.)

The carmine test was also thought to be of value in estimating the degree, but not the type, of constipation which might be present. Since N4 is normal, a reading of $\mathrm{R} 2$ or $3 \mathrm{~N} 5$ may be taken to mean mild constipation, a further delay (N6 or over) as moderate but severe if the initial appearance of carmine is delayed until the fourth day or later (R4 or over). In 5 cases the colour did not return to normal until 9,11 (twice), 12, and 13 days after ingestion, and in another 6 cases only on the eighth day.

Admittedly arbitrary, this subdivision has been made in Table II according to age-group and sex after eliminating the 5 children with a normal transit time. Table II shows that boys are slightly more numerous than girls in the age-group 3-6 years but that they are also likely to be more severely constipated; in the 7-13 age-group these findings $\frac{\text { 응 }}{3}$ are reversed. The difference between the sexes in: the incidence of severe constipation in the twos age-groups is statistically significant at the $1 \%$ level $\overrightarrow{0}$ It is possible that the decline in the degree of constipation in boys over the age of 6 is due to the $\overline{\bar{c}}$. supervention of rectal inertia with resulting faecalo incontinence which notoriously affects more boyso than girls but which expressly excluded them from this series.

TABLE II

Degree of Constipation Related to Age and Sexo

\begin{tabular}{|c|c|c|c|c|c|}
\hline & \multicolumn{4}{|c|}{ Age-groups } & \multirow{3}{*}{ Total } \\
\hline & \multicolumn{2}{|c|}{$3-6$ years } & \multicolumn{2}{|c|}{$7-13$ years } & \\
\hline & Boys & Girls & Boys & Girls & \\
\hline $\begin{array}{l}\text { Mild } \\
\text { Moderate } \\
\text { Severe }\end{array}$ & $\begin{array}{c}5 \\
2 \\
9 \\
(56 \%)\end{array}$ & $\begin{array}{c}4 \\
4 \\
2 \\
(20 \%)\end{array}$ & $\begin{array}{c}4 \\
5 \\
3 \\
(25 \%)\end{array}$ & $\begin{array}{c}5 \\
6 \\
11 \\
(50 \%)\end{array}$ & $\begin{array}{c}18 \\
17 \\
25 \\
(42 \%)\end{array}$ \\
\hline Total & 16 & 10 & 12 & 22 & 60 \\
\hline
\end{tabular}

$\chi^{2}=6 \cdot 74 ;$ df $=1 ; p<0.01$.

\section{Discussion}

Carmine was first used as a marker at the turn of the century mainly for the purpose of studying the physiology of bowel motility. It was first useक clinically to determine the transit time in infantso by Triboulet (1909), in toddlers by Lesné, Binet, and Paulin (1920), and in adults by Strauss (1914) Strauss found that the normal range was 12 to $48^{\circ}$ hours but that the drier the stools the longer the transit time, which, in rectal constipation, could exceed 5 to 6 days. Rothman and Katz (1964) stated that 10 grains $(0.6 \mathrm{~g}$.) given with food was usually excreted $40-48$ hours later, with only 2 . trace of carmine to be seen in the first part of the stool passed on the third day; they regarded the test as 'simple, inexpensive and accurate'. However, Mulinos (1935) reported greater variability $38 \%$ of his students saw most of the carmine in the first stool passed and $50 \%$ in the second stool irrespective of whether food had been taken with the marker or not; but the frequency of boweh actions in his sample seems to have been extraf ordinarily erratic. In children, Wolman (1957) found that on average carmine first appeared ir 20 hours and disappeared 48 hours after ingestion a transit time which he claims approximates closel to that found in adults.

It may therefore be concluded from the literature that in unconstipated subjects stools passed on th fourth day should be free of carmine and this iक्षे 
entirely consistent with the present evaluation of the test in children, which shows it to be a fairly reliable index of transit time. However, though the carmine test in this study can discriminate almost completely between the two selected groups, the constipated and the normal, it cannot of course be expected to afford an equally clear-cut distinction in heterogeneous clinical material in which a wider scatter of the normal range may possibly be obtained.

Within these limitations, it can be used clinically as an adjunct to physical examination to determine the presence and severity of constipation in a child in order to adjust treatment accordingly and to assess how successful it has been. It is not suggested that every child with constipation should be treated, indeed this would be a serious retrograde step, but some of the more severe cases of simple constipation, rectal in type, will, if left alone, ultimately develop rectal inertia. In this condition reflex inhibition of the external sphincter occurs before any sensation of fullness in the rectum, and so faecal incontinence will follow (Callaghan and Nixon, 1964). Boys in particular are prone to this complication and so the more severe the degree of constipation the more essential it becomes for appropriate measures to be introduced to prevent this disaster. Theoretically the carmine test should also be of value in children who have already started soiling, to try and differentiate the purely psychogenic cases from those with rectal inertia; in practice this has proved to be somewhat disappointing, but the results will be documented in due course. On the other hand, the carmine test has thrown some light on the perplexing problem of recurrent abdominal pain in children (Dimson, 1968).

The author wishes to thank Dr. J. H. Baron for his help with the statistical analyses.

\section{REFERENCES}

Alvarez, W. C., and Freedlander, B. L. (1924). The rate of progress of food residues through the bowel. Fournal of the American Medical Association, 83, 576.

Burnett, F. L. (1923). The intestinal rate and the form of the feces. American fournal of Roentgenology, 10, 599.

Callaghan, R. P., and Nixon, H. H. (1964). Megarectum: physiological observations. Archives of Disease in Childhood, 39, 153.

Davidson, M., Kugler, M. M., and Bauer, C. H. (1963). Diagnosis and management in children with severe and protracted constipation and obstipation. fournal of Pediatrics, 62, 261.

Dimson, S. B. (1968). Chronic constipation related to recurrent abdominal pain and to acquired encopresis. In Memoirs XII International Congress of Pediatrics, vol. 3, p. 570. Ed. by 'J. Kumate. Impresiones Modernas, Mexico City.

Dykes, P., Harris, P., and Marston, A. (1960). Treatment of dry mouth. (Letter to the Editor.) Lancet, 2, 1353.

Hinton, J. M. (1967). Laxatives and anti-diarrhoeal agents: transit studies. Proceedings of the Royal Society of Medicine, 60, 215.

and classification. Postgraduate Medical fournal, 44, 720.

Hurst, A. F. (1919). Constipation and Allied Intestinal Disorders, 2nd ed., p. 55. Oxford Medical Publications. London.

Lesné, E., Binet, L., and Paulin, A. (1920). La traversée digestive chez le nourrisson variations biologiques et pathologiques. Archives de médicine des Enfants, 23, 449.

Mulinos, M. G. (1935). The value of selective drugs in the treatment of constipation. Review of Gastroenterology, 2, 292.

Reid, J. J. A. (1956). The regular use of laxatives by schoolchildren. British Medical fournal, 2, 25.

Rothman, M. M., and Katz, A. B. (1964). Analysis of feces. Carmine or charcoal bowel motility test. In Gastroenterology, 2nd ed., vol. 2, p. 695 . Ed. by H. L. Bockus. Saunders, Philadelphia.

Shanks, S. C., and Kerley, P. (1958). A Textbook of X-Ray Diagnosis, vol. 3, 3rd ed., p. 367. Lewis, London.

Strauss, H. (1914). Zur Verwendung der Karminprobe für die Bestimmung der Verweildauer im Verdauungskanal Archiv für Verdauungskrankheiten, mit Einschluss der Stoffwechselpatholgie und der Diätetik, 20, 299.

Triboulet, M. H. (1909). Durée de la traversée digestive chez l'enfant normale et chez l'enfant malade: épreuve du carmine. Bulletins de la Sociéte de Pédiatrie de Paris, 11, 512.

Wolman, I. J. (1957). Laboratory Applications in Clinical Pediatrics, p. 696. McGraw Hill, New York.

Correspondence to Dr. S. B. Dimson, Sydenham Children's Hospital, London S.E.26. 